\title{
GENEALOGICAL CHART
}

The immediate ancestors, close relatives, and children of Gilbert du Motier and Adrienne de Noailles, marquis and marquise de Lafayette

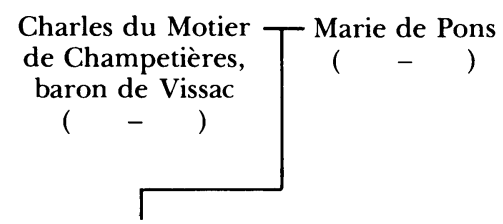

Edouard du Motier, marquis de Lafayette (first member of junior branch of Du Motier family to hold the title)

$(-1740)$

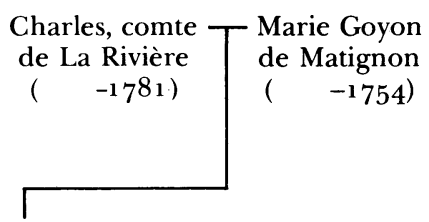

Joseph, marquis J Julie de La Rivière de La Rivière $\quad(1721-1753)$ -1770 )

$-1773)$$$
\text { (2) }
$$

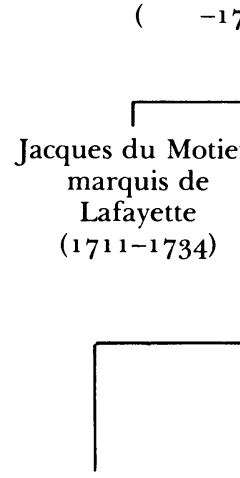

Marie de Guerin ("Mlle de Chavaniac")

$$
\text { ( } 175^{6-1} 77^{8)}
$$

m. marquis d'Abos (1756-1807)

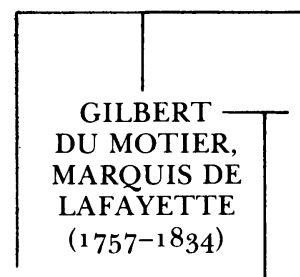

Marie-LouiseJacqueline de Lafayette (176o-176o)

\begin{tabular}{ccc}
\hline & & \\
ADRIENNE & Clotilde de & Pauline de \\
DE & Noailles & Noailles \\
NOAILLES & $(1763-1788)$ & $(1766-1839)$ \\
$(1759-1807)$ & m. (1) Scipion de & m. Joachim \\
& Beauvoir, & de Montagu- \\
& marquis & Beaune, marquis \\
& du Roure & de Bouzols \\
& $\left(\begin{array}{l}-1782) \\
\end{array}\right.$ & $(1764-1834)$
\end{tabular}

(2) Joseph, vicomte Gilbert - Julie du Motier, de La marquis de Rivière Lafayette (1732-1759) de Thésan ( - )

George-Washington, marquis de Lafayette (1779-1849) m. Emilie Destutt de Tracy (1780-186o)
Virginie de Lafayette (1782-1849) $\mathrm{m}$. Louis, marquis de Lasteyrie (1 781-1826) 


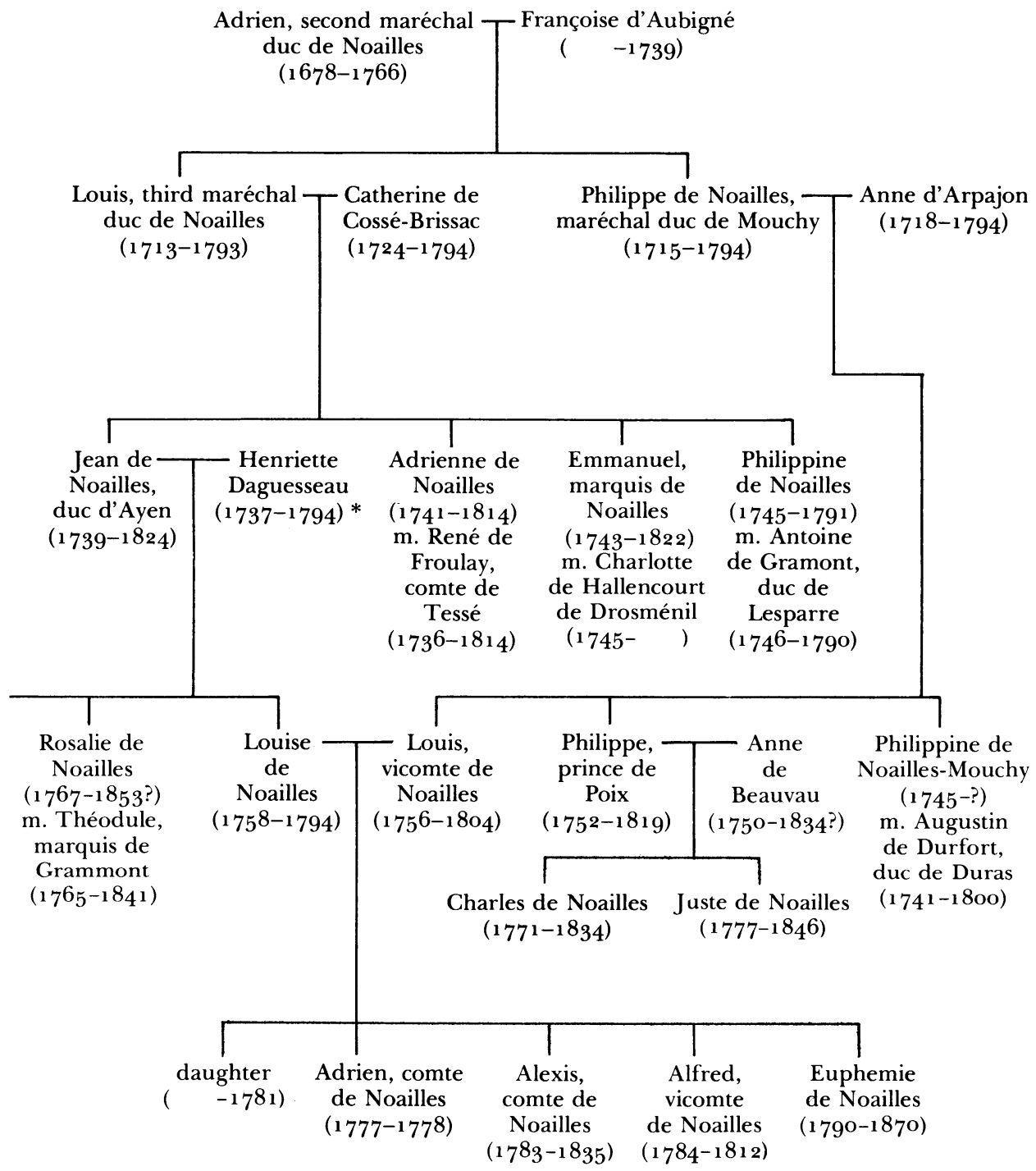

* Antoinette Daguesseau (sister of Henriette)

( $175^{6-1828)}$

m. Louis, comte de Ségur

(1 753-1830) 

Lafayette in the Age of the American Revolution 
